\title{
OS MÉTODOS DE ENSINO, CURRÍCULO E A PROFISSIONALIZAÇÃO DOCENTE: QUAIS RELAÇÕES? ${ }^{1}$
}

\author{
André Luiz Sena Mariano ${ }^{2}$
}

\begin{abstract}
Resumo
O texto argumenta sobre a centralidade dos métodos de ensino para a formação e a profissionalização docente. Debruça-se em uma análise do currículo de um curso de Pedagogia de uma universidade pública do interior do Estado de São Paulo com o propósito de compreender as maneiras pelas quais as discussões alusivas aos métodos de ensino se fazem presentes nas disciplinas ofertadas. As análises são tecidas à luz do materialismo cultural de Raymond Williams. Advoga a importância de se compreender que, tão relevante quanto o conteúdo a ser ensinado, é a discussão das formas como esse conteúdo é transformado nos cursos de formação inicial. Defende que são eles o elemento que permite distinguir o ofício docente dos demais ofícios de nossa sociedade, dando-lhe, portanto, especificidade.
\end{abstract}

Palavras-chave: Métodos didático-pedagógicos. Currículo. Profissionalização do docente.

\section{THE TEACHING METHODS, THE CURRICULUM AND TEACHER PROFESSIONALIZATION: WHICH RELATIONS?}

\begin{abstract}
This paper argues about the central place of the teaching methods to teachers formation and professionalization. Addresses an analysis of an Education course curriculum of a public university from the interior of São Paulo State aiming to understand by which ways the discussions regarding teaching methods are presented in the offered subjects. The analysis are made in the light of Raymond Williams cultural materialism. Supports the importance of understanding that the discussion of the means by which the contents are transformed in initial training courses are just as relevant as the content to be taught. Defends that they are the element which allows distinguish teaching labour from others in our society, therefore giving it specificity.
\end{abstract}

Keywords: Didactic-pedagogical methods. Curriculum. Teacher professionalization. 


\section{INTRODUÇÃO}

Este texto tentará, num primeiro momento, argumentar sobre a centralidade dos métodos de ensino para a formação de professores e para a profissionalização docente; num segundo momento, fará uma análise do currículo de um curso de Pedagogia de uma universidade pública do interior do Estado de São Paulo com o propósito de compreender as maneiras pelas quais as discussões alusivas aos métodos de ensino se fazem presentes nas disciplinas ofertadas por esse curso; encerra advogando a importância de se compreender que, tão relevante quanto o conteúdo a ser ensinado, é a discussão concernente às formas como esse conteúdo é transformado nos cursos de formação inicial.

O campo da formação de professores tem se consagrado com uma das áreas da pesquisa educacional que, quantitativamente, tem produzido um dos maiores números de estudos. Muitos são os trabalhos de levantamento bibliográfico que, ao analisar essa produção tanto sob o viés quantitativo quanto qualitativo, revelam que esse alto número de estudos não é acompanhado de uma diversificação quanto ao foco.

Nesse sentido, André (2000), em um primeiro trabalho de estado da arte que analisou as pesquisas entre 1990 e 1998, sinalizava que havia um foco bastante acentuado nos estudos sobre a formação inicial e um bom número de trabalhos sobre formação continuada, identidade, profissionalização docente e os aspectos culturais apareciam como focos emergentes das pesquisas. Porém, em outro trabalho (ANDRÉ, 2007), a autora começa a sinalizar para uma preocupação quanto à redução de pesquisas sobre a formação inicial; ganham espaço os trabalhos sobre formação continuada, sobre identidade docente e, também, sobre a prática pedagógica.

Em um terceiro levantamento, André (2010) reitera a constatação feita nos trabalhos anteriores: a de que os estudos sobre prática pedagógica, identidade e profissionalização docente, que colocam o acento na figura do professor, conseguem significativo destaque, levando, por outro lado, a um decréscimo de pesquisas sobre a formação inicial.

De acordo com a autora, essa ampliação de foco é positiva. Porém,

\footnotetext{
Outro apontamento importante a fazer é que tal concentração na temática do professor desviou a atenção dos pesquisadores dos cursos de formação inicial. Desde o início dos anos 2000 vem caindo radicalmente o número de estudos sobre formação inicial, chegando a $18 \%$ do total das pesquisas em 2007. Esse fato causa muita preocupação porque ainda há muito a conhecer sobre como preparar os docentes para enfrentar os desafios da educação no século XXI. (ANDRÉ, 2010, p. 177).
}

A partir da afirmação da autora, pode-se inferir, também, que, além dessa redução quantitativa, os focos das pesquisas restringem-se cada vez mais: aqueles que ainda se debruçam sobre a formação inicial de professores, o fazem, de maneira geral, investigando as relações e/ou contribuições dos estágios supervisionados, por concebê-los como momento por excelência para a construção da relação teoria e prática ${ }^{3}$.

Nota-se, então, que muitos aspectos da formação inicial de professores estão despertando pouco interesse dos pesquisadores. Como exemplo disso, a temática da diversidade cultural, tão presente nas polêmicas agendas governamentais e contando com 
vultuosos recursos, não possui o mesmo destaque na pauta das pesquisas. Aborda-se a diversidade presente nas escolas a partir de suas relações com a prática pedagógica e a formação continuada, com o olhar voltado às clivagens de raça/etnia, classe social, gênero/sexualidade, mas pouco se investigam as construções dessa temática na formação inicial. Além disso, percebe-se uma ausência de reflexões sobre as questões mais amplas da dinâmica cultural e de seus impactos nos cursos de formação inicial.

Nos três levantamentos analisados, constata-se pouca discussão sobre as relações entre a formação inicial e os fundamentos epistemológicos da profissão docente. Embora paire o discurso de que os cursos são excessivamente teóricos, encontram-se exíguas pesquisas que tragam elementos para melhor qualificar essa problemática. Agrava-se esse quadro com uma discussão inexistente acerca dos métodos de ensino; muito se discute sobre quais são os conteúdos que configuram a formação docente para a educação infantil e anos iniciais do ensino fundamental ${ }^{4}$, porém, pouco se ausculta sobre as formas de ensinar, ou seja, a autora não menciona, nos três levantamentos, a existência de estudos preocupados com a compreensão da relação entre conteúdo e forma na formação inicial de professores. É sobre essa temática que este texto quer se debruçar um pouco mais.

Para tanto, parte da premissa de que é no curso de formação inicial que a profissionalização da docência começa a ser construída de maneira mais sistemática e orgânica (não desconsiderando que o processo de aprendizagem da docência se inicia antes dos cursos de graduação), sobretudo se são levados em conta os elementos que lhe dão especificidade. E mais: a maneira como os futuros professores irão desempenhar seu ofício guarda fortes relações com as experiências que tiveram na condição de discentes. Todavia, essas relações não podem e nem devem ser compreendidas em termos meramente de reprodução mecânica, ou seja, de que os docentes reproduzem, cabalmente, os modelos aos quais estiveram submetidos durante o processo de formação; esses modelos colaboram para a construção das práticas educativas, mas não as definem.

\section{OS MÉTODOS DE ENSINO COMO ELEMENTO ESPECÍFICO DAFORMAÇÃO E DA PROFISSÃ̃ DOCENTE}

Quando se busca uma melhor compreensão da profissão docente, mormente aquela voltada às etapas iniciais da escolarização, alguns equívocos, pautados em estereótipos, pairam no ar. No que se refere a isso, Gauthier et al (1998), ao tentar esboçar um quadro de elementos que comporiam uma teoria específica da pedagogia, afirmam que:

Uma das condições essenciais a toda profissão é a formalização dos saberes necessários à execução das tarefas que lhe são próprias. Ao contrário de vários outros ofícios que desenvolveram um corpus de saberes, o ensino tarda a refletir sobre si mesmo. Confinado ao segredo da sala de aula, ele resiste à sua própria conceitualização e mal consegue se expressar. Na verdade, mesmo que o ensino já venha sendo realizado há séculos, é muito difícil definir os saberes envolvidos no exercício desse ofício, tamanha é a sua ignorância em relação a si mesmo. (GAUTHIER et al 1998, p. 20). 


\section{Revista HIIST'TEIDBR On-line}

Os autores aprofundam a crítica ao pontuarem que essa indefinição quanto ao que caracteriza o ofício docente permite que se enseje uma desconstrução de seu papel histórico e social específico ao se argumentar que, para ser professor, basta conhecer o conteúdo, ter talento, ter bom senso, seguir sua intuição, ter experiência e ter cultura. Em que pese a importância desses elementos para a configuração da prática pedagógica, nota-se que, amiúde, eles são considerados de maneira isolada e implicam um desprezo por aquilo que a nosso ver - e concordando com Valdemarin $(2010 ; 2014)$ - é o que diferencia a profissão docente dos demais ofícios: os métodos de ensino. Como exemplo disso, não basta ter um excelente domínio de conteúdo se ele não vier acompanhado de uma capacidade técnica - e aqui técnica não é sinônimo de instrumental, mas de um domínio de um saber específico de fazer com que esse conteúdo possa ser ensinado e, consequentemente, aprendido.

Neste texto, não se quer criar ilações de que o domínio de conteúdo deva ficar em segundo plano nos cursos de formação de professores. O que se busca é tentar caminhar, de maneira dialética, para o reconhecimento ineludível de que a docência se caracteriza por uma relação intrínseca entre conteúdo e forma; não basta, por exemplo, conhecer as teorias educacionais relativas ao processo de alfabetização se estas não forem acompanhadas de uma discussão metodológica - que não implica formulação de receitas - mas, o exercício de traçar caminhos para que as formas de se pensar teoricamente esse processo possam encontrar ancoradouros na prática pedagógica e vice-versa. Como outro exemplo, não basta ao professor de História ter um arcabouço de ferramentas que lhe permitam uma excelente leitura e análise das diversas fontes historiográficas, se ele não for capaz de transportar essa habilidade para o interior da sala de aula; um excelente domínio de conteúdo conforma um bacharel; ao professor, além da sólida formação conceitual, requer-se o domínio das técnicas de efetivação do ensino no interior das salas de aula. Tal fato, a nosso ver, já mostra como se pode caminhar na contramão do idealismo de que ser professor é algo demasiadamente simples.

Tal complexidade é corroborada por autores como Tardif (2002) e Gauthier et al (1998), quando pontuam a multiplicidade de saberes que compõem a profissão docente. Os autores preocupam-se em mostrar que, embora a profissão se nutra e se organize de saberes provenientes de diversas fontes, eles estão profundamente imiscuídos. Esses saberes podem ser separados para fins heurísticos, mas, na consecução das práticas pedagógicas, eles estão interconectados. No que tange a isso, os autores argumentam que há, ao menos, seis tipos de saberes para definir a especificidade da profissão docente, quais sejam: os saberes disciplinares, os curriculares, os das ciências da educação, os da tradição pedagógica, o experiencial e os da ação pedagógica ${ }^{5}$.

Preocupados em apresentar premissas para a definição desses saberes, os autores afirmam que os disciplinares correspondem àqueles construídos pelos cientistas e pesquisadores nas diversas áreas do conhecimento e que estão à nossa disposição na sociedade; os curriculares derivam dos primeiros, uma vez que residem nas inúmeras transformações pelas quais uma disciplina passa para se tornar, efetivamente, um programa de ensino; os das ciências da educação ancoram-se nos conhecimentos profissionais que o professor precisa dominar e que colaboram, diretamente, para o ato de ensinar, ou seja, são elementos que colaboram para uma melhor condução das práticas internas às unidades escolares; o experiencial - aquele que não pode ser ensinado pelas instâncias formadoras, 
porque não fazem parte do conhecimento epistêmico - é aquele proveniente do exercício cotidiano da profissão e que, por vezes e a julgar pelas manifestações do senso comum, acaba se tornando o único necessário à profissão docente; os da tradição pedagógica estão relacionados a uma veiculação histórica do que é ser professor e que vem perpassando, ao longo do tempo, o ofício. Nesse sentido, parece que muitas práticas pedagógicas se ancoram ora no saber experiencial ora no saber da tradição, uma vez que todos os docentes passaram anos de suas vidas nos bancos escolares; embora esses saberes não sejam científicos, são elementos que também configuram o ofício do professor, a escola não é uma instituição totalmente desconhecida aos docentes e os modelos de prática pedagógica ao qual estiveram submetidos influenciam na formação do ofício docente. Por último, mas não menos importantes, há os saberes da ação pedagógica, aqueles que mais podem contribuir para um processo de profissionalização da docência.

Para Gauthier et al:

\begin{abstract}
Não poderá haver profissionalização do ensino enquanto esse tipo de saber não for mais explicitado, visto que os saberes da ação pedagógica constituem um dos fundamentos da identidade profissional do professor. De fato, na ausência de um saber da ação pedagógica válido, o professor, para fundamentar seus gestos, continuará recorrendo à experiência, à tradição, ao bom senso, em suma, continuará usando saberes que não somente podem comportar limitações importantes, mas também não o distinguem em nada, ou em quase nada, do cidadão comum. (1998, p. 34).
\end{abstract}

Este saber, denominado pelos autores de saber da ação pedagógica, é aquilo que chamamos aqui, sem que essa nomenclatura seja nova, de "métodos de ensino". Ao teorizar sobre as apropriações da Escola Nova no Brasil, Valdemarin define que "[...] o método de ensino é configurado num repertório de regras comuns, simplificadas, que podem ser entendidas, memorizadas e repetidas por todos os leitores de modo a participarem, mesmo que discursivamente, das inovações pretendidas". (VALDEMARIN, 2010, p. 21).

E ainda acrescenta a autora:

O método de ensino é apresentado como o recurso pedagógico capaz de atender às demandas da sociedade, formando indivíduos portadores das habilidades básicas, como ler, escrever, calcular, e que valoriza o progresso científico e industrial de modo a dar-lhe prosseguimento por meio da formação escolar. (VALDEMARIN, 2010, p. 21).

Isso mostra a profunda conexão que há entre métodos de ensino e demandas histórico-sociais, ou seja, eles não são organizados e produzidos de maneira aleatória e à revelia da sociedade e, tampouco, se configuram como mero reflexo de demandas maiores. Talvez, uma das crises da atual relação entre escola e sociedade seja a dificuldade de encontrar um método de ensino que responda de maneira mais abrangente possível ao momento contemporâneo que vivemos. Se se quer pensar elementos que permitam uma discussão profunda acerca da profissionalização docente, eles, necessariamente, passam pela definição dos métodos de ensino coadunados aos outros saberes que compõem a profissão docente. 


\section{Revista HIIST'TEIDBR On-line}

Artigo

doi: $10.20396 /$ rho.v17i4.8645844

Sabemos bem que a discussão dos métodos de ensino não é nova e remonta, por exemplo, ao educador morávio Jan Amós Comenius que, no século XVII escreve um tratado intitulado "Didática Magna", a fim de argumentar que a ineficiência do ensino vigente à época era corolário de um problema de métodos deficientes. (COMENIUS, 2010). Sabemos, também, que há vários estudos na área de História da Educação que focalizam os diferentes métodos de ensino ${ }^{6}$ e suas influências na organização do trabalho pedagógico. Contudo, o que se procura é resgatar a centralidade dos métodos de ensino para a definição do ofício de professor; tal centralidade não permite, entretanto, inferir que o seu domínio é condição suficiente para o exercício do magistério. Os métodos de ensino se não esgotam em si a complexidade da profissão - tal qual já tentamos mostrar - são elementos nevrálgicos em torno dos quais a docência se organiza.

A centralidade dos métodos de ensino é evidenciada por Alves (2005), ao discorrer sobre a organização da escola moderna. Nesse sentido, os métodos não são centrais só para o ofício do professor, mas também para a instituição escolar. Ao traçar a configuração histórica dos métodos e da escola, o autor lança o conceito de "trabalho didático". A discussão proposta por ele não descarta os métodos de ensino na organização da docência, mas incorpora outros elementos que ampliam a compreensão da complexidade da profissão. Para tanto, ele argumenta que o trabalho didático deve ser compreendido em pelo menos três aspectos: é uma relação educativa que coloca, frente a frente, as figuras do professor e do aluno como agentes históricos específicos; ação que se realiza com a mediação de recursos didáticos; e implica a necessidade de espaços físicos específicos para sua ocorrência. A partir disso, é possível inferir que os métodos se referem ao segundo aspecto do trabalho didático proposto pelo autor. Mais uma vez, é possível apontar que eles não esgotam a docência, mas são condição sine que non para defini-la ante os demais ofícios.

Ao apontarmos acerca da relevância desses estudos históricos para a constituição dos métodos de ensino, não se incorre no equívoco de adoção de uma postura saudosista que clama pelo retorno de uma instituição que, durante séculos, esteve inacessível a uma parcela significativa de nossa população e, tampouco, procura-se transpor para nosso século os métodos que foram fecundos em outra época histórica. De acordo com Alves, reconhecer a importância, por exemplo, do método estabelecido na Didática Magna de Comenius, não significa que ele seja capaz de responder aos nossos anseios atuais. Para ele:

[...] as novas tecnologias vêm sendo incorporadas pelas escolas não no sentido de transformar a relação educativa e ajustá-la às necessidades de nossa época, mas, sim, no intuito de reforçá-la. Portanto, a forma de organização do trabalho didático dominante na escola tornou-se anacrônica, pois aferrada ao século XVII e incapaz de cumprir uma função social relevante em nossos dias. Não é essa escola comeniana que pode formar o cidadão demandado pela sociedade, hoje. (ALVES, 2005, p. 140).

O autor, cuidadosamente, ao mesmo tempo em que procura ressaltar que os métodos de ensino que bem responderam a uma dada época podem não responder a outra, não incorre no equívoco de prescindir de que a docência mantenha aquilo que lhe é específico. Eis o desafio: encontrar métodos que coadunem a organização curricular, o uso de tecnologias e, mais ainda, permitam que a escola não continue sendo criticada por seu suposto arcaísmo. 


\section{Revista HIISTEYIDIR On-line}

O que se pode perceber, tanto nas afirmações de Alves (2005) quanto nas de Valdemarin (2010), é que os métodos são chamados a responder a uma necessidade social: a formação de um tipo de sociabilidade. Com isso, é possível afirmar que eles não se forjam e se configuram como artefatos isolados de um contexto mais amplo, mas estão inextricavelmente inseridos numa dada configuração histórica e social.

A complexidade da profissão docente, conforme tentamos mostrar até aqui, não se esgota no domínio de métodos de ensino ou dos conteúdos específicos, não obstante sejam elementos fulcrais para a execução do ofício. Além desses elementos relacionados aos múltiplos saberes que poderiam ensejar sua profissionalização, a docência e, consequentemente, os métodos precisam ser compreendidos em um cenário mais amplo, qual seja: o contexto cultural.

Não significa que enveredemos para um debate acerca dos conceitos de relativismo e universalismo cultural. Tal qual o fazem Gauthier et al (1998), reconhecemos que a docência é um ofício universal, no sentido de que está presente em todos os espaços da terra e tem perpassado diferentes épocas históricas. Ao contrário, o que tentamos argumentar, ao defender que o contexto cultural seja considerado, repousa nas palavras de Forquin (1993) quando afirma, peremptoriamente, que toda prática educativa é necessariamente algo que ocorre no interior de uma seleção cultural; a educação, mormente a escolar, não é capaz de levar para o interior das salas de aula todos os elementos disponíveis na esfera cultural, precisando estabelecer uma seleção de conteúdos destinados à formação da nova geração; esse movimento de seleção também é feito nos cursos de formação inicial.

Para tanto, Forquin, ancorando-se em Verret e Chevallard, recorre ao conceito de transposição didática. De acordo com ele:

[...] a educação escolar não se limita a fazer uma seleção entre os saberes e os materiais culturais disponíveis num dado momento, ela deve também, para tornálos efetivamente transmissíveis, efetivamente assimiláveis às jovens gerações, entregar-se a um imenso trabalho de reorganização, de reestruturação, ou de 'transposição didática'. (FORQUIN, 1993, p. 16).

A transposição didática se concretiza, se materializa no interior da sala de aula, por meio dos métodos de ensino. São eles que permitem que os elementos da cultura, a partir dos quais os conhecimentos escolares são definidos, se transformem em algo que possa ser ensinado e, por conseguinte, aprendido. São eles os responsáveis por transformar o conhecimento científico em saberes escolares.

Isso significa, então, que pensar os métodos de ensino a partir do pressuposto de que toda educação é necessariamente uma prática cultural e que são eles que, por meio da transposição didática, materializam os elementos culturais na sala de aula, nos impinge o reconhecimento de que a cultura é o grande pano de fundo em torno do qual a profissão se organiza. Nesse sentido, é possível remeter a Mellouki e Gauthier (2004) quando afirmam que o professor é um trabalhador cultural, responsável pela decodificação desses aspectos no interior das salas de aula dos diferentes níveis de ensino.

Dessa forma, além de pensar na multiplicidade de saberes que compõem o ofício docente, a assunção do professor como um trabalhador cultural leva-nos ao postulado de que o professor e os métodos estão imbricados nos meios de produção da vida humana. No que 
se refere a isso, Williams (1979), ao sistematizar seu materialismo cultural, advoga que a cultura é, para além do econômico, um fator que precisa ser reconhecido na esfera de produção da vida humana. Para ele, a cultura não é uma tradição idealista, separada dos conflitos que estão postos no tecido social, e, tampouco, uma esfera que só reproduz a ordem econômica vigente.

Embora o autor, em função de sua formação e atuação, se ocupe em analisar as obras de arte e as manifestações literárias, nos traz importantes elementos a serem agregados à defesa e argumentação da centralidade dos métodos de ensino para a formação e a profissão docente. Forquin (1993), embora teça algumas críticas à maneira como Raymond Williams concebe a cultura comum e seu potencial para a organização do sistema educativo ${ }^{7}$, recorre ao conceito de "tradição seletiva" (WILLIAMS, 1979), para erigir seus argumentos sobre a necessária seleção cultural que é feita pela educação escolar.

Para as discussões que aqui nos interessam mais diretamente, tentaremos levantar, para fins heurísticos, três aspectos. Em primeiro lugar, é possível inferir que essa tradição seletiva proposta por Williams e trazida ao campo educacional por Forquin, seja verificada na organização curricular. É o currículo que, tanto no seu âmbito formal quanto no prático, opera, diuturnamente, os mecanismos que organizam o conhecimento escolar. É por meio dele que as unidades escolares e as instituições formadoras de professores identificam as mudanças e permanências dos/nos saberes escolares. Isso posto, somos instados a reconhecer, em segundo lugar, que a transposição didática se materializa nos métodos de ensino e, efetivamente, são eles que permitem a transformação dos conhecimentos científicos em saberes escolares. Em terceiro e não menos importante: se, tal qual sugere Williams $(1979,2013)$, a cultura é um modo de produção da vida humana, se toda prática educativa é uma prática cultural e, como consequência disso, são os métodos de ensino que levam os elementos da cultura para o interior da sala de aula, somos levados a afirmar que os métodos de ensino são modos de produção da vida. São eles os grandes responsáveis pela formação do tipo de sociabilidade que a escola deseja construir em seus estudantes. E mais ainda: a abordagem deles, desde o curso de formação inicial, é elemento decisivo para que a profissionalização docente possa ser requerida e sentida já nessa etapa da formação.

Em outras palavras, se o currículo, tal qual defende Silva (2004), produz subjetividades e é nele que ocorre a tradição seletiva, transformando conhecimento científico em conteúdos escolares, significa, então, que tão importante quanto a discussão relativa ao quê é ensinado e ao porquê é ensinado, é retomar a discussão acerca do como se ensina. Nesse sentido, essas três esferas - o quê, o porquê e o como (conteúdo, visão política e forma) - são os elementos da prática e que devem, durante a formação, ser concebidos como os elos garantidores da necessária relação entre conteúdo e forma.

Na próxima sessão, passamos a nos dedicar à análise concernente à maneira como os métodos de ensino se fazem presentes no projeto pedagógico de um curso de Pedagogia de uma instituição pública do interior do Estado de São Paulo.

\section{OS MÉTODOS DE ENSINO NO CURRÍCULO DO CURSO DE PEDAGOGIA: QUAL LUGAR?}




\section{Revista HIISTEYIDIR On-line}

Encontrar as possíveis abordagens do tema em pauta no projeto pedagógico do curso de Pedagogia mostrou-se um caminho fecundo para erigir uma tentativa de compreensão de quais são os lugares que os métodos ocupam na formação inicial de professores. Com isso, é preciso reconhecer que o projeto do curso não é, aqui, analisado somente como um documento que expressa suas intenções legais; mais do que isso, ele é um artefato curricular que forja um tipo de sociabilidade nos alunos. Claro está que, tal qual defende Goodson (1995), um currículo escrito - forma como o projeto é aqui entendido - configura-se como um currículo pré-ativo, ou seja, algo anterior à prática e que não necessariamente se efetiva tal qual fora planejado.

A respeito da importância de se tecerem análises sobre o documento escrito, Goodson afirma que:

[...] é politicamente ingênuo e conceitualmente inadequado afirmar que 'o importante é a prática em sala de aula' (da mesma forma que é uma ignorância querer excluir a política da educação). O que importa ainda, e mais obviamente nesse caso, é compreender os parâmetros anteriores à prática. O que também deveria ser claro, no entanto, é que não são simplesmente as definições intelectuais que emanam do currículo escrito as que possuem força. (1995, p. 21).

É possível perceber que a análise de um currículo é bastante complexa e multifacetada. Sabemos que um empreendimento que se restringe a um documento não consegue verificar os desdobramentos efetivos no terreno da prática. Todavia, dados os imperativos que se colocam para um texto dessa natureza, o foco de problematização ficará restrito ao documento por entendê-lo como algo pouco estudado - um momento anterior à prática dos cursos de formação inicial - e, sobretudo, porque, tal qual Goodson (1995) defende, o currículo escrito é capaz de, criar uma tradição, uma tradição seletiva. (WILLIAMS, 1979).

No que se refere a isso, foram analisados os programas de ensino que constam do projeto pedagógico ainda vigente, datado de 2006, de todas as disciplinas obrigatórias da estrutura curricular. Nela, foram auscultados os itens relativos às ementas e aos conteúdos programáticos. Considerando-se, então, as definições de Valdemarin (2010) sobre métodos de ensino e de Alves (2005) sobre trabalho didático - categoria mais ampla que abrange os métodos de ensino em um de seus aspectos - foram levantados os elementos que ou se reportam explicitamente ou potencialmente às discussões sobre métodos; neste caso, para o termo potencialmente, foram consideradas as menções que, a despeito de não utilizarem explicitamente os termos métodos de ensino, metodologias ou procedimentos didáticos apresentavam elementos conceituais que permitiriam inferir potenciais para a construção dessa discussão.

A estrutura curricular analisada é composta por 41 disciplinas obrigatórias organizadas em dois núcleos: o de Estudos Básicos e ou de Aprofundamento e Diversificação de Estudos. No primeiro núcleo, encontram-se os componentes curriculares mais próximos à formação do especialista em educação, bem como aqueles relativos à formação docente para as etapas iniciais da escolarização; no segundo núcleo, as disciplinas alocadas podem ser concebidas como aquelas que, em maior ou menor grau, refletem às especificidades do corpo docente do curso ${ }^{8}$. 


\section{Revista HIIST'TEIDBR On-line}

Para este trabalho de análise, três hipóteses foram lançadas: haveria uma discussão sobre os métodos de ensino nas disciplinas da área de História da Educação, sobretudo no que se refere a uma tentativa de compreensão da instituição escolar e dos métodos que foram criados em cada contexto específico; haveria essa discussão, embora com outro foco, nas disciplinas da área de Didática, inclusive considerando que os métodos, reverberados em discussões relativas ao processo ensino-aprendizagem, são objetos centrais e que deram origem a esse campo disciplinar; discussões sobre os métodos nas disciplinas mais afeitas aos conteúdos e metodologias específicos.

Na leitura dos itens constantes do conteúdo programático dos planos de ensino e na análise das ementas, percebe-se que há disciplinas que trazem discussões explicitamente voltadas aos métodos de ensino seja na nomenclatura, na ementa e/ou no conteúdo programático; ao passo em que há outras que trazem menções potenciais para a discussão na ementa e/ou no conteúdo programático; e disciplinas que silenciam o tema, por razões várias e que não serão aprofundadas neste texto. Para que fosse possível erigir tais considerações, foram levados em conta os elementos que estão atrelados aos métodos, isto é, não foi focalizada, somente, uma abordagem específica para a discussão, mas privilegiadas as menções aos aspectos atinentes aos modos de ensino. Dessa forma, todos os assuntos relativos à preocupação sobre o processo de ensino foram aqui destacados como explícita ou potencial para as análises.

Há aquelas que trazem a discussão de métodos de ensino já em sua nomenclatura, a saber: Conteúdo, Metodologia e Prática de Ensino de Alfabetização, de Ciências, de História e Geografia, de Língua Portuguesa e de Matemática. Neste grupo de disciplinas, percebe-se, também, que quatro apresentam na ementa, de maneira explícita, elementos para as discussões relativas aos métodos de ensino. Nesse sentido, na ementa da disciplina Alfabetização, encontra-se o seguinte "estudos dos fundamentos conceituais e orientações metodológicas para a alfabetização de crianças"; na disciplina História e Geografia, está registrado em sua ementa "procedimentos didáticos. Projetos de ensino"; na disciplina Ciências, aparece escrito "análise de propostas metodológicas. Material didático para a educação científica"; por fim, na disciplina Matemática, está expressa a preocupação com "material didático para a educação matemática". A disciplina Língua Portuguesa é a única deste bloco - com o termo metodologia no nome - que não traz explicitamente termos da discussão metodológica, mas apresenta germes que potencializam sobremaneira a discussão: em sua ementa, lê-se que "serão apresentados aos alunos instrumentos que possibilitem operar com a categoria gênero e discurso".

Aqui, as discussões metodológicas acabam sendo tratadas por meio do termo "instrumentos", algo para o qual já procuramos mostrar que é necessária uma abordagem cuidadosa. Discutir e requerer que os métodos de ensino sejam tratados como o elemento nevrálgico da docência não pode significar que isso se restrinja ao seu domínio isolado de reflexões teóricas e que incorram numa postura de instrumentalização e, consequente, pauperização da prática pedagógica a ser desenvolvida pelos futuros professores. E o contrário também se faz verdadeiro: uma reflexão teórica, por mais relevante e necessária que seja, se não se mostra capaz de produzir efeitos práticos, pouco contribui para uma organização efetiva em que o método seja capaz de ensinar o conteúdo escolar da melhor maneira possível. 


\section{Revista HIIST'TEIDBR On-line}

Uma análise dos conteúdos programáticos desse bloco disciplinar revela que todas trazem explicitamente a discussão metodológica em suas unidades temáticas. A disciplina Alfabetização, em uma de suas unidades, propõe-se a discutir "Aspectos metodológicos", subdivididos em: 1) Os métodos tradicionais de alfabetização; 2) Análise de Cartilhas; 3) O método fônico de alfabetização; 4) O método Paulo Freire; 5) A abordagem sócioconstrutivista da alfabetização; 6) A abordagem sócio-histórica da alfabetização. Na disciplina História e Geografia, uma das unidades se propõe a discutir "Linguagens, recursos tecnológicos e as metodologias para o ensino de História e Geografia". Para a disciplina Ciências, há proposta de discussão acerca dos "conteúdos de ciências na Educação Infantil e no ensino fundamental: enfoques teóricos e metodológicos nos eixos ambiente, ser humano e saúde, terra e universo e recursos tecnológicos". Na disciplina Matemática, há o seguinte registro "conteúdos matemáticos na educação infantil e nos anos iniciais do Ensino Fundamental: enfoques teóricos e metodológicos nos eixos números e operações, espaço e forma, grandezas e medidas e tratamento da informação". Por fim, a disciplina Língua Portuguesa, em seu conteúdo programático, apresenta o seguinte texto: "O fato de os objetivos do ensino de Língua Portuguesa consistir em ensinar os alunos e produzir e interpretar textos orais e escritos e de se considerar os gêneros discursivos uma categoria operatória no ensino da Língua Portuguesa levar-nos-á a refletir sobre conteúdo, metodologia e prática de ensino de Língua Portuguesa a partir dos textos que se seguem $[\ldots] "$.

A partir desses elementos, temos a confirmação de uma de nossas hipóteses: as disciplinas mais voltadas às discussões metodológicas, desde o termo até a definição de seus conteúdos programáticos, apresentam elementos que deixam bastante evidenciada uma preocupação com problematizações relativas aos domínios dos métodos de ensino e caberia uma investigação de como esses desdobramentos são evidenciados no cotidiano do curso.

Além dessas disciplinas, encontramos menções à preocupação com os métodos de ensino em outro bloco formado por: História da Educação, Filosofia da Educação, Filosofia para Crianças e Pedagogias da Infância. De certo modo, a outra hipótese que lançamos, alusiva ao fato de o tema estar presente nas disciplinas da área de História da Educação, se confirmou. No que se refere ao elemento textual das ementas, encontramos em duas disciplinas da área a seguinte redação: "Os tópicos abordam a evolução e os impasses das universidades, colégios e escolares elementares e seus métodos"; em outra disciplina da área, o texto diz que "[...] será estudada a constituição do sistema escolar brasileiro, num período que abrange desde o século XIX até a década de 90 do século XX". Percebe-se, assim, que, enquanto em uma disciplina o foco na discussão é explícito, na outra encontram-se elementos que podem potencializar essa discussão.

No que se refere aos conteúdos programáticos, em uma disciplina encontra-se uma unidade denominada "as bases sócio-culturais dos projetos formativos"; na outra "os projetos dos educadores e a constituição do campo educacional".

Foram encontradas menções, ainda, em duas disciplinas da área de Filosofia da Educação. Em uma delas, com foco nas discussões de Filosofia para Crianças, revela-se o seguinte texto: "A proposta Filosofia para Crianças de Matthew Lipman: metodologia, fundamentos teóricos e currículo". Em outra disciplina de Filosofia da Educação, encontrase na ementa abordagem de "teoria do conhecimento e educação. Processo de conhecimento 


\section{Revista HIISTEYIDIR On-line}

Artigo

doi: $10.20396 /$ rho.v17i4.8645844

e processo de ensino. Relação entre sujeito e objeto no processo de conhecimento e no processo de ensino".

Quando se verificam os desdobramentos dos conteúdos programáticos de ambas as disciplinas, na disciplina voltada à Filosofia para Crianças, uma unidade programática centra-se nos "fundamentos, metodologia e currículo da proposta de Filosofia para Crianças de Matthew Lipman; na outra disciplina, as discussões acerca dos métodos de ensino estão distribuídas em duas unidades: em uma, encontra-se "a relação entre sujeito e objeto no processo de conhecimento e no processo de ensino" e, em outra, "o papel do pensamento e da ação no processo de conhecimento e no processo de ensino".

Na disciplina Pedagogias da Infância, não se encontra registro dessa discussão em sua ementa, mas encontra-se uma unidade programática com a seguinte problematização: "vida, obra e proposta pedagógica de pelo menos dois autores clássicos da Educação da Infância".

A terceira hipótese levantada por este texto não se confirmou: as duas disciplinas da área de Didática não apresentam, nem explícita ou potencialmente, elementos para discussões relativas aos métodos de ensino.

O que chama a atenção, nesse aspecto, é o silenciamento das disciplinas da área de Didática, que teve, em sua gênese, uma acentuada preocupação com os métodos de ensino, chegando, amiúde, a ser confundida com o estudo exclusivamente do tema. Talvez, essa ausência de discussões seja corolário da existência de cinco disciplinas mais especificamente voltadas às questões metodológicas. Nesse caso, salta aos olhos, a julgar pelos elementos textuais, que algumas disciplinas podem incorrer na crítica fundamental a qual Boulos (2008), por exemplo, chama a atenção no que tange a pensar a organização da didática. Para a autora, "[...] o método de ensino, que tem sido obscurecido pela abordagem instrumentalista que se caracteriza pela consideração isolada e desconexa de técnicas e procedimentos de ensino, sem referência a seus fundamentos mais gerais". (2008, p. 96).

Além desses elementos, faz-se importante destacar aqui a própria alteração empreendida no interior do campo científico. (BOURDIEU, 2005). No que se refere a isso, convém lembrar a obra "A didática em questão" (CANDAU, 2002), organizada a partir do seminário homônimo ocorrido no início da década de 1980, em que os pesquisadores lançavam as discussões que a didática passasse a se ocupar da multidimensionalidade do processo de ensino-aprendizagem. Essa virada epistemológica acabou afastando de seu escopo o estudo dos métodos de ensino, mormente, se for considerada a dimensão tecnicista que prevaleceu definindo o tom da abordagem durante décadas. Dessa forma, além de o estudo de métodos poder contar com um "espaço privilegiado" para tal, ganha novos contornos ao ser desconectado da área que lhe deu origem.

É evidente que a crítica de um estudo descontextualizado dos métodos se ancora nos fragmentos textuais dos programas de ensino e não pode ser generalizada à prática cotidiana do curso; para isso, seria preciso outro estudo que foge aos propósitos deste texto. O que se pode evidenciar, a partir dos programas, é que os métodos de ensino parecem ter sido deslocados de lugar.

No que se refere a isso e utilizando os termos de Williams (1979), se há uma tradição seletiva que nos leva a inferir que os métodos de ensino sejam elementos dominantes no 


\section{Revista HIIST'TEIDBR On-line}

Artigo

doi: $10.20396 /$ rho.v17i4.8645844

campo da Didática, o advento de disciplinas mais metodológicas, além de, aparentemente, desconectar essa discussão desse campo originário, traz outros contornos ao ser alocada no interior de disciplinas ${ }^{9}$ que, a julgar pela forma como estão retratadas no currículo pré-ativo, são espaços por excelência da relação conteúdo-forma.

Outro aspecto é aquele que parece dar o tom de uma nova tradição na abordagem dos métodos de ensino. Quando nos referimos a essa nova tradição, recorremos aos argumentos de Goodson (1995), que reconhece a capacidade de o currículo pré-ativo atuar no estabelecimento e na invenção de tradições. Com isso, estamos querendo afirmar que os métodos de ensino estão sendo mais abordados pelas disciplinas da área de história da educação, sobretudo quando coadunados à formação do sistema educacional brasileiro.

Essa situação nos leva a concordar com Alves (2005) ao argumentar que o estudo do passado representa um caminho fecundo para um processo de compreensão da escola pública na sociedade atual, mormente quando se intenta inventariar as formas de produção e organização dessa instituição. Nesse sentido, não cabe aqui erigir teorizações sobre a complexa história das disciplinas escolares (CHERVEL,1990), contudo, faz-se mister reconhecer o seu caráter criativo e produtivo ao estabelecer uma tradição e, mais do que isso, no que se refere ao ensino superior, reconhecer, como o faz o autor, que uma disciplina está muito mais imiscuída no interior do campo científico que numa escola básica. Tal fato nos permite inferir que as discussões no interior de uma disciplina no ensino superior, em que pesem as tradições, tendem a sofrer alterações mais rápidas por estarem diretamente envolvidas na configuração do campo científico e nas determinações dos saberes a serem ensinados nos outros níveis de ensino.

Um último aspecto a ser evidenciado reside no fato de os métodos de ensino serem abordados por duas disciplinas da área de Filosofia da Educação e, também, a forma como estão expressos na disciplina Pedagogias da Infância. No que se refere a isso, identificamos uma conexão profunda entre os métodos e seus pensadores, a partir de uma premissa de que esses métodos são expressões das ideias pedagógicas. Valdemarin (2010) ajuda a elucidar essa abordagem feita pelas disciplinas ao afirmar que "[...] o método de ensino é apresentado como um conjunto de procedimentos, derivados de uma teoria do conhecimento que atribui aos sentidos o ponto de partida da formação das ideias e dos pensamentos claros". (VALDEMARIN, 2010, p. 15).

Dessa forma, o curso em pauta, parece estar marcado por três tendências: uma primeira, que procura discutir os métodos e suas aplicações diretas aos conteúdos específicos a serem ensinados nas escolas básicas; uma segunda com o estudo a partir de uma perspectiva histórica, procurando compreender as suas influências na organização do sistema de ensino; e uma terceira que busca conectá-los aos seus pensadores, ensejando, junto com as disciplinas de história, abordagens mais contextualizadas das ideias pedagógicas em tela.

Se, como foi apresentado no início, os métodos de ensino são os elementos que inserem a profissão docente em uma abordagem de produção da vida humana, ao reconhecer sua atuação na dinâmica cultural, é possível estabelecer alguns nexos de aproximação ao materialismo cultural de Raymond Williams. No que tange a isso, o curso revela uma tradição que foi quebrada: a abordagem dos métodos de ensino, ao ser deslocada do interior da Didática, ao mesmo tempo em que ganha novos contornos, leva essa área do 


\section{Revista HIISTEYIDIR On-line}

Artigo

doi: $10.20396 /$ rho.v17i4.8645844

conhecimento a uma reconfiguração, bem como responde à correlação de forças no interior do campo científico.

A despeito da defesa de que métodos são os elementos centrais que podem ensejar a construção de uma profissionalização docente, é preciso reconhecer que tem se estabelecido uma tradição que parece sinalizar para um caráter arcaico, obsoleto, de suas discussões. Ao mesmo tempo em que uma abordagem construída pelas disciplinas mais afeitas ao campo das ciências da educação - neste caso, história e filosofia - podem permitir uma compreensão mais ampla acerca de sua gênese, desenvolvimento e desdobramentos, pode dar a entender que o tema pouco tem a ver com a sociedade contemporânea. Dessa forma, falar de métodos de ensino, ainda que se defenda sua centralidade, parece ser algo que só faz sentido a partir de um viés teórico que pauperiza as discussões, ao entendê-las como algo que diz respeito a um passado distante e estanque.

Se assim o fosse, caberia o questionamento: por que, mesmo apesar de parecer um tema obsoleto, a discussão permanece em disciplinas que carregam nomenclaturas diferentes? É possível pensar um curso de formação de professores e a própria profissionalização da profissão sem uma abordagem multidimensional do elemento que a torna específica ante os demais ofícios? Quais caminhos podem ser trilhados para que a centralidade dos métodos de ensino, em uma sociedade cada vez mais tecnológica, possa ser reconhecida, ainda que os métodos adquiram outras conformações? Se não se pode, numa sociedade complexa, reduzir a formação e a profissionalização ao domínio dos métodos de ensino, sabe-se, também, que deles o ofício não pode prescindir, sob risco de incorrermos no equívoco já tão criticado pela literatura, de desqualificar as instâncias formadoras e, como consequência disso, advogar a premissa de que nada há que defina o ser professor a não ser uma questão de vocação ou dom inato.

Dessa forma, ainda que a abordagem dos métodos de ensino ganhe novos contornos, emergindo a partir de discussões múltiplas que perpassam diferentes áreas do conhecimento, essa é a tradição em torno da qual esse oficio parece ainda se ancorar.

\section{CONSIDERAÇÕES FINAIS}

Os estudos sobre formação de professores, ao intentarem argumentar acerca da necessidade e da importância de se consolidar a profissionalização docente, precisam considerar a existência dos elementos que a distinguem dos demais ofícios exercidos na sociedade. No que tange a isso, todos os ofícios possuem inúmeros saberes provenientes de várias fontes que permitem a configuração da especificidade do exercício profissional.

Para a docência, como tentarmos explicitar anteriormente, não basta ter experiência - elemento que só se adquire no cotidiano da profissão, ou seja, um professor iniciante teria de enfrentar óbices ao seu ofício -, não basta ter cultura e não basta ter domínio de conteúdo. Esses elementos precisam ser acompanhados de uma capacidade técnica, de um saber-fazer, para a transposição didática, que consiste, basicamente, em transformar os conhecimentos que são selecionados no interior de uma tradição cultural em conteúdos cognitivos que possam ser ensinados e aprendidos. E é essa capacidade que, a nosso ver, dá o tom da especificidade da docência: a transformação do conhecimento em conteúdos escolares, por 
Artigo

doi: $10.20396 /$ rho.v17i4.8645844

meio da transposição didática, se efetiva nos métodos de ensino. E este é um desafio aos cursos de formação inicial de professores: abordar métodos de ensino que melhor respondam à nossa sociedade contemporânea, sem prescindir de uma compreensão histórica de sua gênese e desenvolvimento, bem como ensejar uma compreensão mais contextualizada e que não incorra na adoção de receitas prontas e mero ensino de técnicas isoladas. Essa melhor resposta não se reduz a mera adequação da escola às demandas atuais, mas, sobretudo, ao reconhecimento de que a escola muda a medida em que a sociedade muda, a escola está imersa no processo histórico da humanidade.

Se os métodos não são os únicos constituidores da docência, e reconhecemos isso, tampouco, os cursos de formação podem prescindir da abordagem desses elementos. No caso do curso analisado, nota-se que a didática parece não mais se ocupar dessa discussão, a despeito de ter sido o seu movimento originário; as disciplinas metodológicas parecem encontrar dificuldade em construir um estudo mais contextualizado sobre a origem e desenvolvimento deles; ficando, pelo que consta nos programas de ensino, as disciplinas da área de História da Educação, Filosofia da Educação e, também, a Pedagogias da Infância com a preocupação em vincular tal discussão aos seus precursores.

Isso demonstra que o curso em pauta parece ir desde uma perspectiva mais ampla e contextualizada das discussões sobre os métodos, até uma abordagem mais instrumentalizada, termo que inclusive aparece em um dos programas de ensino. Não descartarmos o domínio desse instrumental, mas entendemos que deve estar acompanhado das discussões que dão origem a ele, ou seja, os métodos só existem porque foram projetados por pessoas em contextos sociais e históricos bastante diferenciados e isso precisa ser abordado.

É preciso, ainda, salientar que o projeto do curso, por meio de suas ementas e dos conteúdos programáticos nele expressos, não é mero reflexo de intenções individuais ou macrossociais. O que pode ser depreendido é que, em primeiro lugar, esse currículo préativo sofre as intercorrências das forças internas ao campo científico, sobretudo se lembrarmos as aproximações que Chervel (1990) defende entre o campo e as disciplinas no ensino superior; em segundo lugar, também sofre ingerências das alterações que se imprimem ao longo do tempo na concepção de currículo, que, dentre outras coisas, pode ser decorrente de uma maior definição dos temas que compõem uma determinada área do conhecimento. Em terceiro lugar, há as idiossincrasias: ainda que os elementos objetivos possam ser o mesmo e o currículo pré-ativo se organize a partir desses fatores concretos, eles não são decodificados da mesma forma. A esse respeito, caberia, por exemplo, uma investigação daquilo que Williams (1979) chama de consciência prática, ou seja, investigar aquilo que, de fato, os professores fazem em seu cotidiano. Com isso, ainda que seja um documento aparentemente estático, não é mero reflexo, pois, além de responder a esses fatores, também é capaz de construir uma nova tradição.

Em suma, o que se percebe é que a profissionalização da docência passa desde um caráter mais técnico até uma preparação mais sólida acerca dos usos e do desenvolvimento desses métodos ao longo do tempo, procurando compreender que o nosso século XXI, ainda que torne a profissão docente cada vez mais complexa e exija dela elementos constantes de mudança, permite a permanência dos métodos de ensino. Em termos propostos por Williams (1979), são os métodos de ensino que garantem uma continuidade predisposta e o 
estabelecimento de uma tradição seletiva; é essa tradição que coloca a docência na esfera de produção da vida humana. Ao entender que a docência é uma prática cultural e que os métodos são a materialização dessa prática nas salas de aula somos instados a reconhecer que eles são elementos fulcrais na produção da vida humana. Todavia, essa produção da vida humana, no interior dos espaços escolares, reconhece que se forjam sujeitos que, em grande medida, não conseguirão atuar de maneira ampla e irrestrita nos domínios da vida cotidiana, mas, atuarão de maneira efetiva. Em outras palavras, não se prepara futuros professores para atuar como agentes transformadores de e em todas as esferas da sociedade, pois isso seria ingenuidade idealista; forjam-se profissionais para atuar de maneira efetiva, com sólido domínio de conteúdos e métodos, nos espaços privilegiados a tal finalidade.

Assim, entendemos que os métodos não podem ser estudados ora em seu caráter instrumental ora em seu caráter enciclopédico, mas devem estar profundamente conectados com a compreensão do tipo de aluno que se deseja formar e para qual tipo de sociedade. Ou seja, caminhar na interconexão, tal qual propõe Valdemarin (2010), de um estudo dos métodos aliados às ideias pedagógicas e à vida dos estudantes pode ser um caminho fecundo para a construção dos elementos que distinguem a profissão docente dos demais ofícios.

\section{REFERÊNCIAS}

ALVES, G. L. O trabalho didático na escola moderna: formas históricas. Campinas, SP: Autores Associados, 2005.

ANDRÉ, M. A pesquisa sobre formação de professores no Brasil (1990-1998). In: CANDAU, V. (Org.). Ensinar e aprender: sujeitos, saberes e pesquisas. Rio de Janeiro: DP\&A, 2000. p. 83-99.

ANDRÉ, M. Desafios da pós-graduação e da pesquisa sobre formação de professores. Educação \& Linguagem, ano 10, n. 15, p. 43-59, jan./jun. 2007.

ANDRÉ, M. Formação de professores: a constituição de um campo de estudos. Educação, Porto Alegre, v. 33, n. 3, p. 174-181, 2010.

ARARAQUARA. Projeto Pedagógico. Curso de Pedagogia, Faculdade de Ciências e Letras de Araraquara UNESP, 2006.

BOULOS, Y. Didática geral ou especial? Uma contribuição ao debate. In: PICONEZ, S. C. B. (Org.). A prática de ensino e o estágio supervisionado. 15. ed. Campinas, SP: Papirus, 2008. p. 91-99.

BOURDIEU, P. Os usos sociais da ciência: por uma sociologia clínica do campo científico. São Paulo: Ed. da UNESP/INRA, 2005.

CANDAU, V. (Org.). A didática em questão. 21. ed. Petrópolis, RJ: Vozes, 2002.

CHERVEL, A. História das disciplinas escolares: reflexões sobre um campo de pesquisa. Teoria \& Educação, n. 2, p. 177-229, 1990. 
Artigo

doi: $10.20396 /$ rho.v17i4.8645844

COMENIUS, J. A. Didática Magna. São Paulo: Martins Fontes, 2010.

CUNHA, M. I. da. O bom professor e sua prática. Campinas, SP: Papirus, 1989.

FORQUIN, J. Escola e cultura: as bases sociais e epistemológicas do conhecimento escolar. Porto Alegre, RS: ArtMed, 1993.

GAUTHIER, C. et al. Por uma teoria da pedagogia: pesquisas contemporâneas sobre o saber docente. Ijuí, RS: Ed. da UNIJUÍ, 1998.

GOODSON, I. Currículo: teoria e história. 2. ed. Petrópolis, RJ: Vozes, 1995.

MELlOUKI, M.; GAUTHIER, C. O professor e seu mandato de mediador, herdeiro, intérprete e crítico. Educação e Sociedade, v. 25, n. 87, p. 537-571, ago. 2004.

NEVES, Fátima M. O método lancasteriano e a formação disciplinar do povo (São Paulo 1808-1889). 2003. 293 f. Tese (Doutorado em História) - Universidade Estadual Paulista, São Paulo, 2003.

PIMENTA, S. G. (Coord.). Pedagogia, ciência da educação? 5. ed. São Paulo: Cortez, 2006.

PIMENTEL, M. da. G. B. O professor em construção. Campinas, SP: Papirus, 2007.

SILVA, T. T. Documentos de identidade: uma introdução às teorias do currículo. Belo Horizonte, MG: Autêntica, 2004.

TARDIF, M. Saberes docentes e formação profissional. Petrópolis, RJ: Vozes, 2002.

VALDEMARIN, V. T. Estudando as lições de coisas. Campinas, SP: Autores Associados, 2004.

VALDEMARIN, V. T. História dos métodos e materiais de ensino: a escola nova e seus modos de uso. São Paulo: Cortez, 2010.

VALDEMARIN, V. T. Os sentidos e a experiência: professores, alunos e métodos de ensino. In: SAVIANI, D. et al. O legado educacional do século XX no Brasil. 3. ed. Campinas, SP: Autores Associados, 2014. p. 153-190.

WILLIAMS, R. A política e as letras. São Paulo: Ed. da UNESP, 2013.

WILLIAMS, R. Marxismo e Literatura. Rio de Janeiro: Zahar, 1979.

WILLIAMS, R. Recursos da esperança. São Paulo: Ed. da UNESP, 2015.

WILLIAMS, R. The long revolution. Austrália: Pelican Book, 1961. 


\section{Revista HIISTESIBR Dn-lime}

Notas

${ }^{1}$ Texto oriundo de pesquisa realizada em nível de estágio pós-doutoral junto à Faculdade de Ciências e Letras da Universidade Estadual Paulista, campus de Araraquara, e com financiamento do CNPq, na modalidade de bolsa pós-doutorado júnior.

${ }^{2}$ Professor Adjunto do Instituto de Ciências Humanas e Letras e do Programa de Pós-Graduação em Educação da Universidade Federal de Alfenas (alsmariano@yahoo.com.br).

${ }^{3}$ Mais recentemente, é possível verificar, a partir do banco de teses da CAPES, a emergência significativa de estudos sobre a formação inicial com foco no Programa Institucional de Bolsas de Iniciação à Docência (PIBID).

${ }^{4}$ Aqui, estão sendo consideradas as pesquisas que se restringem aos cursos de pedagogia. Portanto, não são analisadas as demais licenciaturas.

${ }^{5}$ Faz-se mister lembrar que essa discussão está longe de ser consensual. Os pressupostos aqui apresentados ancoram-se na literatura da área de formação de professores que toma a epistemologia da prática como referencial. Contudo, essas ideias são adotadas unicamente naquilo que se refere a pensar elementos para a profissionalização docente. Acerca do estatuto epistemológico da pedagogia e das ciências da educação, consultar Pimenta (2006).

${ }^{6}$ VALDEMARIN (2004), sobre o método de ensino intuitivo; VALDEMARIN (2010), sobre os métodos relativos à Escola Nova; NEVES (2003), sobre o método de ensino mútuo ou lancasteriano; ALVES (2005), sobre a organização do trabalho didático nas escolas brasileiras, discutindo métodos que perpassam desde os jesuítas até métodos até o ensino mútuo.

${ }^{7}$ Embora Raymond Williams não tenha se dedicado a elaboração de uma obra especificamente educacional, ele aborda em inúmeros trabalhos, como The Long Revolution e Recursos da Esperança, por exemplo, as relações estabelecidas entre cultura, sociedade e educação no contexto britânico dos anos 1950 e 1960.

${ }^{8}$ Neste caso, estão alocadas disciplinas tais como: Ação Pedagógica Integrada, Sócio-Antropologia, Cultura e Escola, Filosofia para Crianças, entre outros. No primeiro caso, estão alocadas disciplinas mais tradicionais do curso como aquelas mais atinentes ao campo dos fundamentos da educação (História, Filosofia, Sociologia, Psicologia etc.), aquelas mais voltadas à compreensão da gestão escolar e aquelas mais alusivas às discussões metodológicas (Didática, por exemplo).

${ }^{9}$ Pode-se notar, para além do curso em pauta, que as discussões relativas aos métodos, ainda que ganhem outra nomenclatura e, por vezes, forma, permanece nas dinâmicas curriculares. Além da nomenclatura Conteúdo, Metodologia e Prática de Ensino, encontramos em outros cursos de Pedagogia, ao menos quatro outros nomes que revelam a permanência dessas preocupações, tais como estão exemplificados a seguir: História: conteúdos e seu ensino; História: fundamentos e metodologias; Fundamentos teórico-metodológicos para ensino de; e História: saberes e metodologias.

Submetido em: 06/07/2016

Aprovado em: 25/08/2017 